\section{BMJ Open Respiratory Research}

\title{
Longitudinal change in quality of life following hospitalisation for acute exacerbations of COPD
}

\author{
John Steer, ${ }^{1}$ G John Gibson, ${ }^{2}$ Stephen C Bourke ${ }^{1,2}$
}

To cite: Steer J, Gibson GJ, Bourke SC. Longitudinal change in quality of life following hospitalisation for acute exacerbations of COPD. BMJ Open Resp Res 2015;2: e000069. doi:10.1136/ bmjresp-2014-000069

Additional material is available. To view please visit the journal. (http://dx.doi.org/ 10.1136/bmjresp-2014000069)

Received 20 October 2014 Revised 27 November 2014 Accepted 28 November 2014

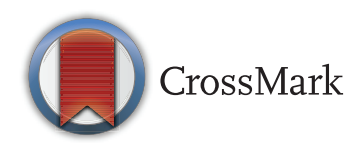

${ }^{1}$ Department of Respiratory Medicine, North Tyneside General Hospital, North Shields, Tyne and Wear, UK ${ }^{2}$ Newcastle University, Newcastle-upon-Tyne, UK

Correspondence to Dr John Steer; john_steer@hotmail.com

\section{ABSTRACT}

Background: Current guidelines for management of patients hospitalised with acute exacerbations of chronic obstructive pulmonary disease (COPD) recommend that clinical decisions, including escalation to assisted ventilation, be informed by an estimate of the patients' likely postdischarge quality of life. There is little evidence to inform predictions of outcome in terms of quality of life, psychological well-being and functional status. Undue nihilism might lead to denial of potentially life-saving therapy, while undue optimism might prolong suffering when alternative palliation would be more appropriate. This study aimed to detail longitudinal changes in quality of life following hospitalisation for acute exacerbations of COPD. Methods: We prospectively recruited two cohorts (exacerbations requiring assisted ventilation during admission and exacerbations not ventilated). Admission clinical data, and mortality and readmission details were collected. Quality of life, psychological well-being and functional status were formally assessed over the subsequent 12 months. Timeadjusted mean change in quality of life was examined.

Results: 183 patients (82 ventilated; 101 not ventilated) were recruited. On average, overall quality of life improved by a clinically important amount in those not ventilated and did not decline in ventilated patients. Both groups showed clinically important improvements in respiratory symptoms and an individual's sense of control over their condition, despite the tendency for functional status to decline.

Conclusions: On average, postdischarge quality of life improved in non-ventilated and did not decline in ventilated patients. Certain quality of life domains (ie, symptoms and mastery) improved significantly. Better understanding of longitudinal change in postdischarge quality of life should help to inform decision-making.

\section{BACKGROUND}

Acute exacerbations of chronic obstructive pulmonary disease (AECOPD) are often accompanied by a decline in an individual's quality of life (QoL). ${ }^{1-3}$ While recovery following AECOPD managed without hospital admission may be unpredictable and prolonged, ${ }^{4} 5$ the time course of recovery

\section{KEY MESSAGES}

Predictions of subsequent quality of life influence important treatment decisions. This is the first study to describe, in detail, Iongitudinal changes in quality of life following hospitalisation for COPD exacerbations and demonstrates that, in the majority of patients, quality of life either improves or does not significantly decline.

Following hospital discharge, most quality of life domains took 3 months to recover to baseline levels. Individuals' activity levels tended to decline following discharge but the reduction was not clinically significant.

- Quality of life was recorded using multiple validated tools to ensure that all aspects of an individual's quality of life and functional status were assessed.

- Previous studies have shown prognostic nihilism is common and non-invasive ventilation is underused in this population. These results should help to inform both clinicians and patients when making important clinical decisions about the appropriateness or otherwise of escalating treatment when the patient's condition potentially warrants it.

following hospitalisation for AECOPD has been infrequently studied and requires clarification.

Clinical guidelines recommend that patients whose QoL is "unlikely to recover to an acceptable level" should not receive assisted ventilation when otherwise indicated. $^{6}$ Implicit in this statement is an assumption that both clinicians and patients can make a reasonable estimate of what an individual's QoL and functional status will be if they survive the acute admission. However, evidence on this point is sparse, with only a single longitudinal study, which suggested that QoL measurements may continue to recover for up to 9 months following hospital discharge. $^{7}$

Despite the prognostic uncertainty, some patients do not receive assisted ventilation because either they or their clinicians expect 
their QoL and/or functional status to be unacceptably poor following hospital discharge. Nava et al surveyed end-of-life decision-making in respiratory critical care units across Europe and rated the reasons for withholding or withdrawing treatment on a scale of 1 (most important) to 10 (least important). They showed that predictions of a poor QoL following discharge (specifically, a poor predicted functional status or assumption by the patient that their QoL postdischarge would be unacceptable) were between the second and fourth most common reasons for limiting treatment. As recommended, therefore, important treatment decisions are being made on the basis of clinicians' and patients' predictions of postdischarge QoL and functional status with very little evidence that such predictions are accurate.

In order to clarify the long-term effects on QoL of hospitalisation for AECOPD, we have performed sequential assessments of surviving patients, both those who required and did not require assisted ventilation, over 12 months following discharge.

'Quality of life' is a broad multidimensional concept which includes evaluation of both positive and negative aspects of life. ${ }^{9}$ Psychological well-being, functional status, general health-related QoL (HRQoL) and respiratory-specific HRQoL are all domains of overall QoL. The definitions of these domains vary in the literature and there is terminological confusion. The assessment tools used in this study aim to evaluate each of these domains individually but they will also be influenced by general changes in individuals' lives (eg, bereavement, unemployment, medical conditions). Consequently, due to terminological uncertainty and the lack of specificity of the individual tools, we have chosen to use the general term 'quality of life' to describe the changes in HRQoL, psychological well-being and functional status that participants experienced.

\section{METHODS}

Patients admitted to two neighbouring hospitals between December 2008 and September 2010 with an acute exacerbation of COPD, and who survived to discharge, were eligible. Participants were approached prior to hospital discharge and written consent obtained. We aimed prospectively to recruit approximately equal numbers of patients with AECOPD who (A) required assisted ventilation for acidaemic respiratory failure (at any point during hospital stay) and (B) did not need ventilation. To ensure that the recruitment rates of the two groups followed comparable timeframes, over each 2-week period all patients receiving assisted ventilation were approached for consent and this number was matched to the number of non-ventilated patients approached over that period. The total population of patients hospitalised with AECOPD during this time period $(n=920)$ has been described in a previous manuscript. ${ }^{10}$

Inclusion criteria were: admission with AECOPD; survival to hospital discharge; a clinical diagnosis of COPD supported by spirometric evidence of airflow obstruction (forced expiratory volume in $1 \mathrm{~s}\left(\mathrm{FEV}_{1}\right) /$ forced vital capacity $<0.70$ ) during a period of clinical stability; age $\geq 35$ years; smoking history of $\geq 10$ cigarette pack years and admission from their primary place of residence. Spirometry data were obtained in most patients from screening hospital and general practice records. A few patients without previous spirometry, but with a history consistent with COPD and predischarge obstructive spirometry, confirmed 6 weeks postdischarge, were included. Patients were not eligible for inclusion if: they had previously been included in the study; they were receiving domiciliary ventilation; they had comorbidity that was expected to limit their life to $<12$ months; they had a primary admission diagnosis other than AECOPD; or they had significant cognitive or sensory impairment (resulting in inability to give informed consent or to complete the questionnaires independently). An acute exacerbation was defined as "an acute worsening of the patient's condition from stable-state, which was sustained and warranted additional treatment". ${ }^{11}$ The presence of radiographic consolidation at hospital admission did not preclude inclusion.

Written consent was obtained from all participants and the study protocol was approved by the NHS Research Ethics Committee.

Sociodemographic details, comorbidity and medication information and admission clinical data (including baseline dyspnoea severity, measured by the Extended MRC Dyspnoea Score) ${ }^{12}$ were collected. Assessments of QoL, based on self-recollection of the preceding month, and health resource use were made once clinical stability had been reached close to discharge from hospital (baseline measurement), and then 6 weeks, 3, 6 and 12 months postdischarge. To avoid selection bias, those unable to attend outpatient clinics were offered a home visit. At each assessment following the index admission, the following were recorded: the number of exacerbations since the last assessment; the number of hospital admissions since the last assessment (including whether assisted ventilation was required) and the length of hospital stay for each admission. At each visit, the St George's Respiratory Questionnaire (SGRQ), ${ }^{13}$ Chronic Respiratory Disease Questionnaire (CRQ),${ }^{14}$ Nottingham Extended Activities of Daily Living Scale (NEADL) ${ }^{15}$ and Hospital Anxiety and Depression Scale (HADS $)^{16}$ were administered. The period of recall for each questionnaire was 1 month. A summary of these tools, and the accepted minimum clinically important differences (MCIDs), is shown in table 1. Any significant medical developments since the previous assessment were also documented. If a patient had died in the interim: date of death; place of death and cause of death were collected.

Variable distribution was assessed by visual inspection of the histogram. Descriptive statistics were used to characterise the patient sample, using proportions, means with SDs or medians with IQRs, where appropriate. 
Table 1 Summary of the quality of life (QoL) questionnaires used

\begin{tabular}{|c|c|c|c|}
\hline Questionnaire & $\begin{array}{l}\text { Range of } \\
\text { possible scores }\end{array}$ & $\begin{array}{l}\text { Minimum clinically } \\
\text { important difference (MCID) }\end{array}$ & Interpretation \\
\hline $\begin{array}{l}\text { St Georges' Respiratory } \\
\text { Questionnaire (SGRQ) }\end{array}$ & $0-100$ & \pm 4 & $\begin{array}{l}\text { Higher scores indicate worse } \\
\text { QoL }\end{array}$ \\
\hline $\begin{array}{l}\text { Chronic Respiratory Disease } \\
\text { Questionnaire (CRQ) }\end{array}$ & $1-7$ & \pm 0.5 & $\begin{array}{l}\text { Lower scores indicate worse } \\
\text { QoL }\end{array}$ \\
\hline $\begin{array}{l}\text { Hospital Anxiety and Depression } \\
\text { Scale (HADS) }\end{array}$ & $\begin{array}{l}0-21 \text { (for each } \\
\text { domain) }\end{array}$ & \pm 1.5 & $\begin{array}{l}\text { Higher scores indicate worse } \\
\text { anxiety or depression }\end{array}$ \\
\hline $\begin{array}{l}\text { Nottingham Extended Activity of } \\
\text { Daily Living Score (NEADL) }\end{array}$ & $0-63$ & \pm 5 & $\begin{array}{l}\text { Lower scores indicate lower } \\
\text { levels of activity }\end{array}$ \\
\hline
\end{tabular}

Bivariate comparisons were performed using Fisher's exact test, Student $\mathrm{t}$ test and Mann-Whitney $\mathrm{U}$ test as appropriate. Mortality data were examined using Kaplan-Meier survival analysis, with groups compared by the log-rank test. Methods used to handle missing QoL data are described below. Missing admission clinical data were uncommon: five patients in the non-ventilated group had no ABG recorded. Where necessary, data were imputed using the expectation-maximisation algorithm ${ }^{17}$ based on our larger $(n=920)$ cohort.

The peak (ie, best) QoL score during follow-up was chosen to represent the time at which QoL had recovered from its baseline level. The mean time between baseline and 'best' QoL described the average recovery time following hospital discharge. In order to obtain a global assessment of QoL change over time, we calculated the time-weighted mean changes $(\bar{\Delta})$ during the follow-up period (see online supplementary figure E1). These were compared to the MCID for the relevant questionnaire (table 1) to estimate whether, on average, an individual's QoL changed by a clinically significant amount.

We have assumed that the change in QoL between assessments was related to time in rectilinear fashion. If a participant failed to attend a follow-up appointment but their QoL was recorded at the next scheduled visit, a time-adjusted average was imputed for the missing value by assuming a linear change between the two data points either side of the missing assessment. If no follow-up visits were attended, the individual was excluded from analyses of longitudinal QoL data. Similar to previous studies, ${ }^{18}{ }^{19}$ for each questionnaire (except HADS), death was equated to the score representing the worst QoL, and if a patient died during follow-up, a linear decrease in QoL was assumed from the value at the last assessment to the time of death.

\section{RESULTS}

Of the 183 patients recruited, 82 received assisted ventilation. During the period of the study, only $6.6 \%$ of patients with COPD exacerbations who developed respiratory acidaemia and did not improve with standard management either refused or were judged unsuitable for assisted ventilation. Compared with non-ventilated patients, ventilated patients: had more severe background COPD and a more severe exacerbation (ventilated patients were more likely to: have previously received assisted ventilation; have lower mean $\mathrm{FEV}_{1} \%$ predicted; have worse stable-state dyspnoea and have been prescribed long-term oxygen therapy); and were more likely to be female (table 2).

At the time of hospital discharge, ventilated patients reported that, prior to hospitalisation, they had less severe respiratory symptoms (lower SGRQ symptom domain, $\mathrm{p}=0.021$ ), but their respiratory symptoms had a greater impact on their emotional function (lower CRQ emotional function domain, $\mathrm{p}=0.061$ ) and they reported lower levels of activity (lower NEADL, $\mathrm{p}<0.001$ ). There were, however, no other differences in QoL (measured using either SGRQ or CRQ) or symptoms of anxiety or depression between the two patient groups.

Most patients $(\mathrm{n}=130,71 \%)$ were rehospitalised during the 12-month follow-up period (median (IQR) readmissions $=1(0-3)$, range $0-15)$. In total, $157(86 \%)$ patients reported at least one episode of AECOPD during follow-up (median (IQR) AECOPD=3 (1-6), range $0-15)$. Ventilated patients were more likely to be readmitted and spent more days in hospital during the 12 months following discharge (table 3). Thirty-five (19\%) patients died during follow-up: mortality was nonsignificantly higher in ventilated compared with nonventilated patients $(23.2 \%$ vs $15.8 \%$; log-rank $p=0.20$; figure 1).

For the whole population $(n=183)$, at the time of hospital discharge, lower self-reported functional status was associated with higher 12-month mortality (mean (SD) SGRQ activity $=77.9(16.3)$ in survivors vs $85(12.8)$ in non-survivors, $\mathrm{p}=0.021$; and median (IQR) NEADL $=38$ $(28-45)$ vs 28 (14-37), $\mathrm{p}<0.001)$. Mortality was also nonsignificantly higher in patients with higher scores in the SGRQ impacts and HADS depression domains $(\mathrm{p}=0.071$ and 0.082 , respectively; see online supplementary table E1). Lower self-reported functional status (SGRQ activity and NEADL) was significantly associated with higher rates of hospital readmission $(\mathrm{p}=0.012$ and $\mathrm{p}<0.001$, respectively; see online supplementary table E2).

Of 732 potential outpatient follow-up assessments, 67 (9\%) visits were not attended: complete follow-up of longitudinal QoL data was available on 152 patients 
Table 2 Comparison of characteristics, admission findings and baseline QoL of ventilated and non-ventilated patients

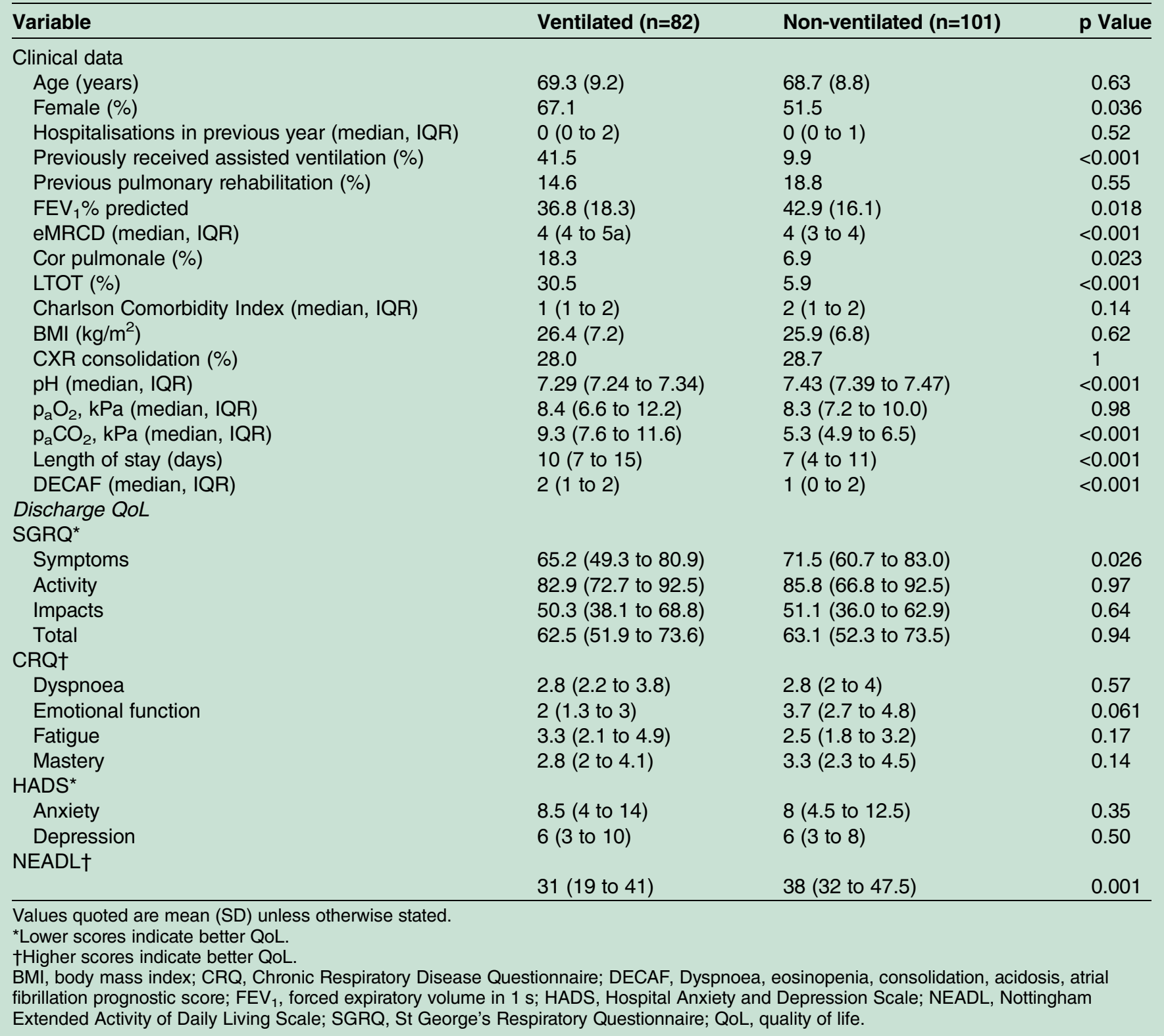

(83.1\%). Online supplementary figure E2 shows details of follow-up attendance during the study. Seven patients did not attend any follow-up appointments following hospital discharge and were therefore excluded from longitudinal QoL analysis.

Most QoL measures peaked at 3 months following discharge, with the exception of activity levels (measured using NEADL and SGRQ activity) which peaked after 6 weeks. For all measures of QoL, except those measuring patient activity (SGRQ activity domain and NEADL), a quarter of patients took 6 months or longer to fully recover (ie, reach their peak QoL). The time course of QoL recovery was statistically similar between ventilated and non-ventilated patients.

In non-ventilated patients, compared with their reported status at discharge, most patients experienced: improved overall QoL ( $\bar{\Delta}$ SGRQ total $=-4.55$ (MCID $=$ $\pm 0.5)$ ); improved respiratory symptoms during the year of follow-up ( $\bar{\Delta}$ SGRQ symptoms $=-11.8(\mathrm{MCID}= \pm 4))$; less impact of their disease on their QoL ( $\bar{\Delta}$ SGRQ impacts= $-5.36(\mathrm{MCID}= \pm 0.5))$; improved sense of control over their condition $(\bar{\Delta} \mathrm{CRQ}$ mastery $=0.87 \quad(\mathrm{MCID}= \pm 0.5))$; and less anxiety $(\bar{\Delta}$ HADS anxiety $=-1.70(\mathrm{MCID}= \pm 1.5)$ ). Non-ventilated patients' activity levels worsened during the 12-month follow-up ( $\bar{\Delta}$ SGRQ activity $=0.60$ and $\bar{\Delta} \mathrm{NEADL}=-2.69)$ although these changes were not clinically significant (table 4). On average, for ventilated patients, overall QoL did not decline following discharge $(\bar{\Delta}$ SGRQ total $=0.05)$ and their respiratory symptoms $(\bar{\Delta}$ SGRQ symptoms $=-4.80)$ and sense of control over their condition $(\bar{\Delta} \mathrm{CRQ}$ mastery $=0.66)$ improved by a clinically important amount. 
Table 3 Health resource use following discharge

\begin{tabular}{llll}
\hline Outcome & Ventilated, $\mathbf{n = 8 2}$ & Not ventilated, $\mathbf{n = 1 0 1}$ & $\mathbf{p}$ Value \\
\hline Readmitted within 12 months (\%) & 76.8 & 66.3 & 0.14 \\
Episodes of AECOPD, median (IQR) & $3(1$ to 6$)$ & $3(1$ to 6$)$ & 0.94 \\
Number of readmissions, median (IQR) & $2(1$ to 3$)$ & $1(0$ to 2$)$ & $1(0$ to 2$)$ \\
Number of respiratory readmissions, median (IQR) & $1(0$ to 3$)$ & $4(0$ to 18$)$ & 0.088 \\
Total length of hospital stay (days), median (IQR) & $11(1$ to 28$)$ & 10.9 & 0.034 \\
Readmission requiring assisted ventilation (\%) & 29.3 & & 0.002 \\
\hline AECOPD, acute exacerbations of chronic obstructive pulmonary disease.
\end{tabular}

Non-ventilated patients had a statistically significantly greater improvement in overall QoL (SGRQ total, $\mathrm{p}=0.019$ ) and respiratory symptoms (SGRQ symptoms, $\mathrm{p}=0.017)$ than those ventilated. Furthermore, the impact of their respiratory disease (SGRQ impacts) improved significantly more in non-ventilated patients $(\mathrm{p}=0.024$; table 4). There were no differences in $\bar{\Delta}$ CRQ, $\bar{\Delta}$ HADS or $\bar{\Delta}$ NEADL between the two groups, although nonventilated patients showed a trend towards greater improvement in activity-specific breathlessness (CRQ Dyspnoea, $\mathrm{p}=0.11$ ).

In approximately $70 \%$ of those ventilated, symptoms and overall QoL improved or remained static following discharge. In non-ventilated patients, overall QoL clinically improved in the majority and only $24 \%$ experienced a clinically significant decline following discharge (table 5).

Within the whole population $(n=176)$, compared with those who were not readmitted during follow-up, readmitted patients had significantly less improvement in QoL for all measures except those assessing depressive symptoms (mean change in HADS depression, $\mathrm{p}=0.50$ ). There were no significant relationships between self-reported exacerbation frequency during follow-up and mean change in QoL (see online supplementary table E3).

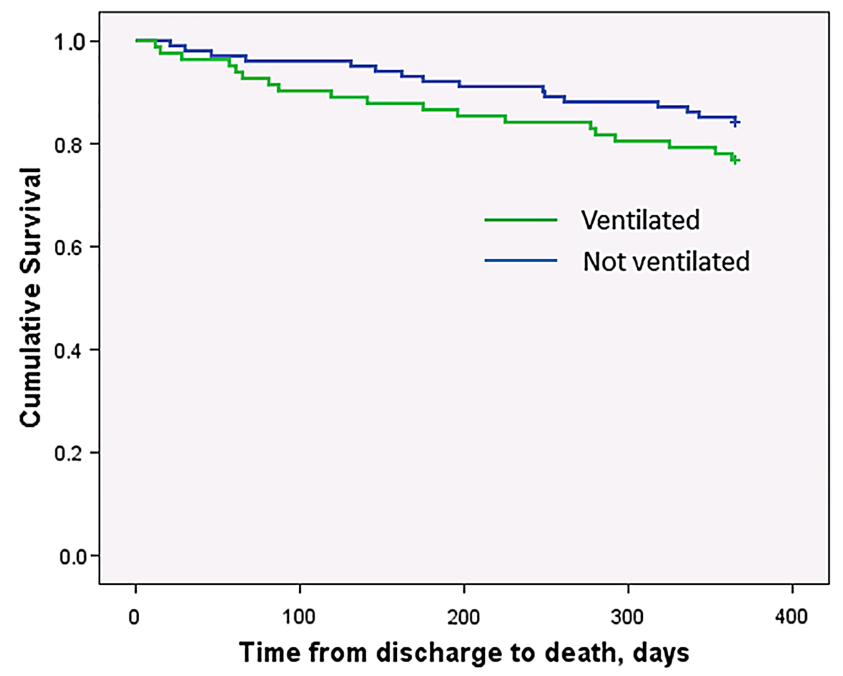

Figure 1 Twelve-month survival of ventilated and non-ventilated patients.

\section{DISCUSSION}

Most patients admitted to hospital with AECOPD did not experience an overall decline in QoL during follow-up, and in certain domains (disease-specific symptoms, mastery of their condition and anxiety levels), QoL improved by a clinically important amount (table 4). In addition, QoL of patients treated with assisted ventilation was, on average, stable or improved during follow-up. The QoL of patients readmitted within 12 months of discharge was significantly poorer than that of those who were not readmitted, but even among readmitted patients, QoL did not decline on average. QoL recovers slowly following discharge with, on average, most QoL domains taking 3 months to recover. Therefore, despite a poor outcome in some individuals, the majority of patients did not experience declining QoL and hence our results suggest that treatment decisions should not be influenced by an assumption that following discharge, a decline in QoL is inevitable.

This is the largest study to date investigating QoL following hospital admission for AECOPD and is the only one to report longitudinal changes over 12 months following discharge. Although COPD is a chronic condition

Table 4 Mean change in QoL over the follow-up period

\begin{tabular}{|c|c|c|c|}
\hline QoL measure & $\begin{array}{l}\text { Ventilated, } \\
n=80\end{array}$ & $\begin{array}{l}\text { Not } \\
\text { ventilated, } \\
n=96\end{array}$ & p Value \\
\hline SGRQ symptoms & $-4.80(19.4)$ & $-11.8(19.2)$ & 0.017 \\
\hline SGRQ activity* & 3.22 (10.2) & 0.60 (13.3) & 0.15 \\
\hline SGRQ impacts* & $-0.09(15.5)$ & $-5.36(14.9)$ & 0.024 \\
\hline SGRQ total $^{\star}$ & $0.05(12.5)$ & $-4.55(13.2)$ & 0.019 \\
\hline CRQ dyspnoea† & $0.17(1.16)$ & $0.48(1.37)$ & 0.11 \\
\hline $\begin{array}{l}\text { CRQ emotional } \\
\text { functiont }\end{array}$ & $0.42(1.10)$ & $0.42(1.16)$ & 0.98 \\
\hline CRQ fatigue† & $0.40(1.12)$ & $0.36(1.20)$ & 0.82 \\
\hline CRQ mastery† & $0.66(1.41)$ & $0.87(1.27)$ & 0.30 \\
\hline HADS anxiety* & $-1.30(2.73)$ & $-1.70(3.76)$ & 0.45 \\
\hline HADS depression* & $-0.43(2.65)$ & $-0.45(3.18)$ & 0.43 \\
\hline NEADL† & $-4.35(8.32)$ & $-2.69(7.64)$ & 0.17 \\
\hline \multicolumn{4}{|c|}{$\begin{array}{l}\text { Values shown as mean (SD). } \\
\text { *Lower values indicate improved QoL. } \\
\text { †Higher values indicate improved QoL. } \\
\text { CRQ, Chronic Respiratory Disease Questionnaire; HADS, Hospital } \\
\text { Anxiety and Depression Scale; NEADL, Nottingham Extended } \\
\text { Activity of Daily Living Scale; SGRQ, St George's Respiratory } \\
\text { Questionnaire; QoL, quality of life. }\end{array}$} \\
\hline
\end{tabular}


Table 5 Clinically important QoL change following hospital discharge

\begin{tabular}{|c|c|c|c|}
\hline SGRQ & $\begin{array}{l}\text { Improved by } \\
\text { more than } \\
\text { MCID*, n (\%) }\end{array}$ & $\begin{array}{l}\text { Neither } \\
\text { improved nor } \\
\text { declined } t \text {, } \\
\text { n (\%) }\end{array}$ & $\begin{array}{l}\text { Declined by } \\
\text { more than } \\
\text { MCID‡, } \\
\text { n (\%) }\end{array}$ \\
\hline \multicolumn{4}{|c|}{ Ventilated, $n=80$} \\
\hline Symptoms & $38(47.5)$ & $19(23.8)$ & $23(28.8)$ \\
\hline Activity & $17(21.3)$ & 28 & \\
\hline Impacts & $34(42.0)$ & $21(26.3)$ & 25 (31.3) \\
\hline Total & $31(38.3)$ & 25 & 24 \\
\hline \multicolumn{4}{|c|}{ Non-ventilated, $\mathrm{n}=96$} \\
\hline Symptoms & $66(68.8)$ & 11( & 19 \\
\hline Activity & $26(27.1)$ & $38(39.6)$ & $32(33.3)$ \\
\hline Impacts & $47(49.0)$ & $25(26.0)$ & $24(25.0)$ \\
\hline Total & $50(52.1)$ & $23(24.0)$ & $23(24.0)$ \\
\hline \multicolumn{4}{|c|}{$\begin{array}{l}{ }^{*} \bar{\Delta} S G R Q \leq-4 . \\
\dagger-4<\bar{\Delta} S G R Q<+4 . \\
\ddagger \bar{\Delta} S G R Q \geq+4 \text {. } \\
\text { MCID, minimum clinically important difference; } \\
\text { SGRQ, St George's Respiratory Questionnaire; QoL, quality of life. }\end{array}$} \\
\hline
\end{tabular}

with a typically progressive course, there are fluctuations in symptom burden and QoL, often related to exacerbations. Previous studies investigating QoL change between only two time points, or widely spaced intervals, will not have adequately reflected this variation and the repeated measurements in our study will better take account of such subtleties. However, the accuracy of our assessment of mean change in QoL could have been improved with even more frequent assessments, but this would have been impractical. We opted to analyse patient death in a similar way to that used in the measurement of preference-based QoL (ie, utility), whereby the lowest possible score on the measurement scale is assigned to indicate patient death. ${ }^{20}$ Although this methodology is not common in QoL studies in stable COPD, it is important to include death in the assessment, because if ignored, the gradual decline in QoL which typically precedes death ${ }^{21}$ will also be ignored. Even though the time course of QoL change, both between assessments and prior to death, may be uncertain and our assumption of a linear change may not fully reflect short-term variation, an area under the curve approach is likely to be a more accurate approximation of true QoL change than comparisons limited to specific time points. QoL was not recorded prior to hospital admission. QoL measured at a point of clinical stability close to the time of hospital discharge was used as the "baseline' measure. Patients were asked to consider their QoL over the preceding month when completing the questionnaires. The effect of their recent hospital admission on their self-reported QoL is uncertain and this methodology may result in an overestimation or underestimation of the QoL improvement during follow-up.

In the present study, the ventilated cohort had severe COPD (table 2), although the 12-month mortality rate was lower than previously reported in comparable studies: $23 \%$ vs approximately $31-49 \% .^{22-24}$ Compared with a similar study from 2002, ${ }^{22}$ our ventilated cohort were younger and had less frequent previous hospitalisations which combined with improvements in postexacerbation management (ie, supported pulmonary discharge and rapid response outreach service) may, in part, explain the lower mortality. We found expected differences between patients who received assisted ventilation and those who did not (table 2), although somewhat surprisingly, those who were ventilated reported less severe COPD symptoms (measured with SGRQ) in the month prior to hospital discharge than those not ventilated (table 2). The ventilated patients may have reported fewer symptoms because they were less active (significant difference in NEADL scores and eMRCD) or because they had had a longer hospital stay and their QoL may have recovered in-hospital to a higher level than that of non-ventilated patients. Furthermore, the effect of surviving a recent lifethreatening illness has on individuals' QoL is uncertain. We are not aware of any publications comparing change in QoL between ventilated and non-ventilated patients. To provide context for our longitudinal QoL data, we have compared the results in the two groups. There are, however, important baseline differences between the two populations (table 2) and therefore the clinical implications of statistically significant differences are unclear. We have highlighted where statistically significant differences were found but would emphasise that the clinically relevant comparison of mean change in longitudinal QoL for each group is with the MCID for that instrument.

There is little published data on longitudinal change in QoL in patients surviving hospital admission for AECOPD. O'Reilly et $a l^{25}$ showed that patient-reported activity limitation and psychological symptoms improved during admission, but deteriorated between hospital discharge and 3 months postdischarge, although the statistical significance of these results is not stated. These results conflict with the only similar study ${ }^{26}$ which showed that patients' symptoms improved progressively from admission (day 0) to day 40 (postdischarge). However, the latter study assessed symptoms whereas O'Reilly et al assessed activity limitation, and neither study interpreted the change in QoL in the context of an MCID. Comparison of these results with ours is complicated by the different time periods investigated, the different QoL components measured and uncertainty over whether the changes identified were clinically important. Andenaes et $a l^{7}$ assessed QoL change (using the SGRQ) over a 9-month period in patients hospitalised with AECOPD. Although not stated, the low in-hospital mortality rate $(3.9 \%)$ suggests that most were not ventilated. Andenaes $e t a l$ showed that, for all SGRQ components except the symptoms domain, QoL was significantly better (both statistically and clinically) at 9 months following discharge than at admission. This differs from our findings (table 4), where non-ventilated 
patients showed an overall improvement in all SGRQ domains except activity. Wildman et $a l^{27}$ showed that $73 \%$ of patients surviving intensive care following an exacerbation of COPD or asthma reported that their QoL was better than or equivalent to before admission, and Connors $e t a l^{28}$ reported that $51 \%$ of patients hospitalised with a severe AECOPD claimed to have good, very good or excellent QoL 6 months after discharge. It is not possible to compare our findings quantitatively with these studies, but the suggestion that patients hospitalised with a severe exacerbation of COPD do not inevitably experience a decline in QoL following discharge is consistent. In our study, improvement in QoL was significantly less in patients who required rehospitalisation within 12 months following discharge than in those not readmitted. There were, however, no differences between those with more or less frequent exacerbations (see online supplementary table E3). It is not possible to state whether it is exacerbation severity or the location of care which impacts on QoL, but this is a finding which merits further study.

Following hospital discharge, in spite of frequent adverse outcomes, the overall QoL of the majority of individuals does not deteriorate from the level experienced during the few weeks prior to hospital discharge, and in many patients, it may improve (table 5). In keeping with national recommendations, ${ }^{6}$ decisions regarding the appropriate ceiling of care are often made on the basis of patients' and clinicians' predictions of subsequent QoL. Incorrect estimates of postdischarge QoL may lead to either: patients being denied potentially beneficial escalation of care; or a prolongation of suffering when palliative approaches may be preferable. These results provide long-term data on expected QoL following hospitalisation for AECOPD and we recommend that poor or declining QoL postdischarge should not be assumed when discussing and making decisions about the appropriateness of escalating treatment when the patient's condition potentially warrants it.

Acknowledgements The authors acknowledge the following for their help with the study: Dr Nick Steen, biostatistician, Newcastle University; the respiratory and acute care physicians at North Tyneside General Hospital and Wansbeck General Hospital; Dr Gbenga Afolabi, Respiratory Physician; Ms Elizabeth Norman and the Respiratory Specialist Nursing Team, North Tyneside General Hospital; the North Tyneside General Hospital Teaching and Research Fellow programme; Breathe North; and the National Institute of Health Research, through the Comprehensive Local Research Network.

Contributors SCB designed and obtained funding for the study. JS performed the literature search and collected the data. JS performed data analysis and interpretation and SCB and GJG supervised it. JS drafted the manuscript. SCB and GJG helped with its revision.

Funding The Breathe North Appeal and Northumbria Healthcare NHS Foundation Trust Teaching and Research Fellow Programme.

Competing interests None.

Ethics approval County Durham \& Tees Valley 1 Research Ethics Committee. Provenance and peer review Not commissioned; externally peer reviewed.

Data sharing statement No additional data are available.
Open Access This is an Open Access article distributed in accordance with the Creative Commons Attribution Non Commercial (CC BY-NC 4.0) license, which permits others to distribute, remix, adapt, build upon this work noncommercially, and license their derivative works on different terms, provided the original work is properly cited and the use is non-commercial. See: http:// creativecommons.org/licenses/by-nc/4.0/

\section{REFERENCES}

1. Seemungal TA, Donaldson GC, Paul EA, et al. Effect of exacerbation on quality of life in patients with chronic obstructive pulmonary disease. Am J Respir Crit Care Med 1998;157(5 Pt 1):1418-22.

2. Doll $\mathrm{H}$, Miravitlles $\mathrm{M}$. Health-related $\mathrm{QOL}$ in acute exacerbations of chronic bronchitis and chronic obstructive pulmonary disease: a review of the literature. Pharmacoeconomics 2005;23:345-63.

3. Esteban C, Quintana JM, Moraza J, et al. Impact of hospitalisations for exacerbations of COPD on health-related quality of life. Respir Med 2009;103:1201-8.

4. Spencer S, Jones PW, Group GS. Time course of recovery of health status following an infective exacerbation of chronic bronchitis. Thorax 2003;58:589-93.

5. Seemungal TA, Donaldson GC, Bhowmik A, et al. Time course and recovery of exacerbations in patients with chronic obstructive pulmonary disease. Am J Respir Crit Care Med 2000;161:1608-13.

6. British Thoracic Society, Royal College of Physicians, The Intensive Care Society. The Use of Non-Invasive Ventilation in the management of patients with chronic obstructive pulmonary disease admitted to hospital with acute type II respiratory failure, 2008. http:// www.brit-thoracic.org.uk/Portals/0/Clinical\%20Information/NIV/ Guidelines/NIVInCOPDFullGuidelineFINAL.pdf (last accessed 6 Oct).

7. Andenaes R, Moum T, Kalfoss $\mathrm{MH}$, et al. Changes in health status, psychological distress, and quality of life in COPD patients after hospitalization. Qual Life Res 2006;15:249-57.

8. Nava S, Sturani $\mathrm{C}$, Hartl S, et al. End-of-life decision-making in respiratory intermediate care units: a European survey. Eur Respir $J$ 2007;30:156-64.

9. The WHOQOL Group. The World Health Organization Quality of Life Assessment (WHOQOL). Development and psychometric properties. Soc Sci Med 1998;46:1569-85.

10. Steer J, Gibson J, Bourke SC. The DECAF Score: predicting hospital mortality in exacerbations of chronic obstructive pulmonary disease. Thorax 2012;67:970-6.

11. Burge S, Wedzicha JA. COPD exacerbations: definitions and classifications. Eur Respir J 2003:41:46s-53s.

12. Steer J, Norman EM, Afolabi OA, et al. Dyspnoea severity and pneumonia as predictors of in-hospital mortality and early readmission in acute exacerbations of COPD. Thorax 2012;67:117-21.

13. Jones PW, Quirk FH, Baveystock CM. The St George's Respiratory Questionnaire. Respir Med 1991;85(Suppl B):25-31; discussion 337.

14. Guyatt GH, Berman LB, Townsend M, et al. A measure of quality of life for clinical trials in chronic lung disease. Thorax 1987;42:773-8.

15. Nouri FM, Lincoln NB. An extended activities of daily living scale for stroke patients. Clin Rehabil 1987;1:301-5.

16. Snaith RP. The Hospital Anxiety and Depression Scale. Health Qual Life Outcomes 2003;1:29.

17. Enders CK. A primer on maximum likelihood algorithms available for use with missing data. Struct Equa Model 2001;8:128-41.

18. Billingham LJ, Abrams KR. Simultaneous analysis of quality of life and survival data. Stat Methods Med Res 2002;11:25-48.

19. Bourke SC, Tomlinson M, Williams TL, et al. Effects of non-invasive ventilation on survival and quality of life in patients with amyotrophic lateral sclerosis: a randomised controlled trial. Lancet Neurol 2006:5:140-7.

20. Feeny DH, Torrance GW. Incorporating utility-based quality-of-life assessment measures in clinical trials. Two examples. Med Care 1989;27(3 Suppl):S190-204.

21. Habraken JM, van der Wal WM, Ter Riet G, et al. Health-related quality of life and functional status in end-stage COPD: a longitudinal study. Eur Respir J 2011;37:280-8.

22. Chu CM, Chan VL, Lin AW, et al. Readmission rates and life threatening events in COPD survivors treated with non-invasive ventilation for acute hypercapnic respiratory failure. Thorax 2004;59:1020-5.

23. Breen D, Churches T, Hawker F, et al. Acute respiratory failure secondary to chronic obstructive pulmonary disease treated in the 
intensive care unit: a long term follow up study. Thorax 2002;57:29-33.

24. Plant PK, Owen JL, Elliott MW. Non-invasive ventilation in acute exacerbations of chronic obstructive pulmonary disease: long term survival and predictors of in-hospital outcome. Thorax 2001;56:708-12.

25. O'Reilly JF, Williams AE, Rice L. Health status impairment and costs associated with COPD exacerbation managed in hospital. Int $J$ Clin Pract 2007;61:1112-20.

26. Koutsokera A, Kiropoulos TS, Nikoulis DJ, et al. Clinical, functional and biochemical changes during recovery from COPD exacerbations. Respir Med 2009;103:919-26.
27. Wildman MJ, Sanderson CF, Groves J, et al. Survival and quality of life for patients with COPD or asthma admitted to intensive care in a UK multicentre cohort: the COPD and Asthma Outcome Study (CAOS). Thorax 2009;64:

128-32.

28. Connors AF Jr, Dawson NV, Thomas C, et al. Outcomes following acute exacerbation of severe chronic obstructive lung disease. The SUPPORT investigators (Study to Understand Prognoses and Preferences for Outcomes and Risks of Treatments) [erratum appears in Am J Respir Crit Care Med 1997;155:386]. Am J Respir Crit Care Med 1996;154(4 Pt 1):959-67. 